\title{
PENGATURAN KESTABILAN HOVER PADA QUADROTOR MENGGUNAKAN KONTROL BACKSTEPPING PD PI
}

\author{
Jumiyatun, Rusdhianto Effendi, dan Joko Susila \\ Jurusan Teknik Elektro, Fakultas Teknologi Industri, Institut Teknologi Sepuluh Nopember \\ email : jum.elektro@gmail.com
}

\begin{abstract}
Abstrak
Quadrotor merupakan jenis pesawat Unmanned Aerial Vehicle (UAV) yang digerakkan oleh 4 buah motor yang terletak di ujung badan utama.Hover merupakan fase terbang yang sangat penting dan harus dimiliki quadrotor agar pemanfaatannya dapat maksimal, dimana ketinggian dan sudut adalah tetap. Kontrol hover merupakan prioritas utama dalam setiap upaya pengendalian quadrotor baik pada fase take-off, landing, dan trajectory. Selain itu, quadrotor merupakan sistem kompleks yang tidak stabil dan dapat menjadi sulit untuk terbang tanpa adanya sistem kontrol. Untuk mengatasi masalah tersebut sangat dibutuhkan suatu algoritma kontroler yang mampu mempertahankan kondisi agar dapat terbang dengan ketinggian dan sudut yang tetap. Kontroller yang digunakan adalah backstepping PD PI. Dari hasil simulasi menunjukkan bahwa kestabilan roll dan pitch, dan yaw dapat tercapai sesuai setpoint yaitu nol dan pengujian ketinggian mendekati tiga karena masih ada error steady state yaitu $0.0132 \mathrm{~m}$.
\end{abstract}

Kata kunci : Quadrotor, Kendali backstepping PD PI, Hover

\begin{abstract}
Quadrotor is typical Unmanned Aerial Vehicle (UAV) plane which moved by 4 motors located in the edge of its main body. Hover is the important flying phase and quadrotor should have it to maximize its use, in which the angle and elevation is constant. Hover control is the main priority in every quadrotor control efforts (take off, landing, and trajectory phases). Moreover, quadrotor is a unstable complex system and becomes difficult to fly without a control system. To solve the problem, a controller algorithm to keep a stable flying condition with constant angle and elevation is required. The required controller is PD PI backstepping. The simulation result showed that yaw, pitch, and roll stability achieved zero set point, while the elevation test showed that the result was next to three as an error steady state existed $(0.0132 \mathrm{~m})$.
\end{abstract}

Keywords: Quadrotor, PD PI Backstepping Control, Hover 


\section{PENDAHULUAN}

Quadrotor adalah salah satu tipe pesawat Unmanned Aerial Vehicle (UAV) yang digerakkkan oleh empat buah motor yang terletak di ujung badan utama. Bagian tengah digunakan untuk peletakan sumber daya (baterai), sistem kontrol, dan sensor. Sistem kontrol tersebut digunakan untuk memberikan sinyal ke driver motor yang digunakan untuk mengatur kecepatan dari tiap-tiap motor sesuai dengan gerakan yang diinginkan. Kecepatan putaran tiap motor bersifat independen tetapi perlu diperhatikan juga efek dari gerakan motor yang satu terhadap motor yang lain. Dengan mengatur kecepatan putaran empat motor tersebut maka quadrotor dapat dikontrol throttle, pitch, yaw, roll-nya.

Ada beberapa penelitian yang berkaitan dengan kontrol quadrotor, beberapa diantara adalah penelitian yang dilakukan Teppo Luukkonen dengan judul Modelling and control of quadcopter, Tommaso Bresciani dengan judul Modelling, Identification and Control of a Quadrotor Helicopter. Dalam penelitian Teppo Luukkonen membahas metode untuk mendapatkan model matematik dari sebuah quadrotor menggunakan persamaan Newton-Euler. Kemudian implementasi sistem kontrol PD kontroler pada quadrotor tersebut [1].

$\mathrm{Mu}$ Huang,et al. membahas tentang masalah kontrol untuk sistem UAV underactuated quadrotor dengan model parameter yang tidak pasti [2]. Teknik yang digunakan berbasis backstepping untuk merancang pengontrol adaptive nonlinear yang dapat mengkompensasi ketidakpastian sistem. A.Rabhi,dkk. membahas tentang pendekatan Fuzzy Takagi-Sugeno dan skema kontroller fuzzy untuk stabilisasi dari sistem quadrotor. Model nonlinier yang pertama dibahas dan kemudian dirancang suatu state umpanbalik controller melalui pendekatan numerical tools (Linear

Matrix Inequalities-LMI). Keuntungan menunjukkan bahwa kontroler yang dirancang menjamin stabilitas sistem global close loop [3].

\section{TEORI}

Teknologi yang terdapat pada quadrotor ini menggunakan sinkronisasi antara keempat rotor yang dikonfigurasikan dalam bentuk frame plus (+) dimana rotor depan dan belakang berputar searah jarum jam, sedangkan rotor sebelah kanan dan kiri bergerak berlawanan arah jarum jam. Quadrotor dapat melakukan take off dan landing secara vertikal.

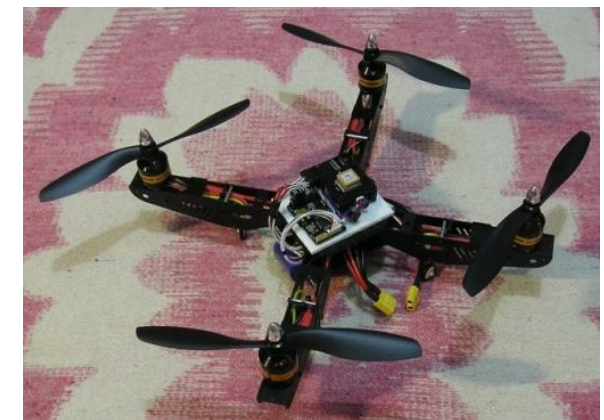

Gambar 1. Bentuk Quadrotor

\section{II.1. Pemodelan Quadrotor}

Pemodelan secara fisik terbilang kompleks, untuk itu harus menggunakan beberapa asumsi sebagai berikut:

1. Struktur dari quadrotor dikatakan rigid

2. Struktur dari quadrotor dikatakan simetris

3. Struktur dari propeller dikatakan rigid

4. Gaya thrust dan drag adalah proporsional dengan kuadrat dari kecepatan propeller

5. Keadaan model adalah keadaan ketika hovering 


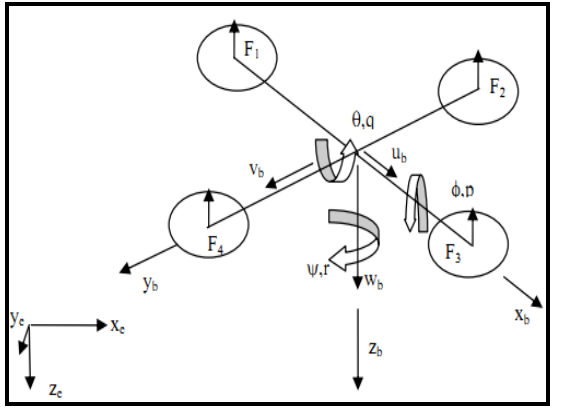

Gamba 2. Ilustrasi B-frame terhadap Eframe

Persamaan kinematika dari 6-DOF rigidbody :

$$
\begin{aligned}
& \xi=J_{\Theta} v \\
& v=\left[V^{B} \omega^{B}\right]^{T}=\left[\begin{array}{llllll}
u & v & w & p & q & r
\end{array}\right]^{T} \\
& J_{\Theta}=\left[\begin{array}{cc}
R_{\Theta} & 0_{3 \times 3} \\
0_{3 \times 3} & T_{\Theta}
\end{array}\right]
\end{aligned}
$$

Matrik rotasi $\left(\mathrm{R}_{\Theta}\right)$ dan matrik translasi $\left(\mathrm{T}_{\Theta}\right)$ ditunjukkan pada persamaan

$$
\begin{gathered}
R_{\Theta}=\left[\begin{array}{ccc}
c \psi c \theta & -s \psi c \phi+c \psi s \theta s \phi & s \psi s \phi+c \psi s \theta c \phi \\
c s \psi c \theta & c \psi c \phi+s \psi s \theta s \phi & -s \psi s \phi+s \psi s \theta c \phi \\
-s \theta & c \theta s \phi & c \theta c \phi
\end{array}\right] \\
T_{\Theta}=\left[\begin{array}{ccc}
1 & \tan \theta \sin \phi & \tan \theta \cos \phi \\
0 & \cos \phi & -\sin \phi \\
0 & \sin \phi / \cos \theta & \cos \phi / \cos \theta
\end{array}\right]
\end{gathered}
$$

persamaan Euler-Newton pada persamaan

$$
\left[\begin{array}{cc}
m I & 0 \\
0 & J
\end{array}\right]\left[\begin{array}{c}
\dot{v}^{b} \\
\dot{\omega}^{b}
\end{array}\right]+\left[\begin{array}{c}
\omega^{b} \times m v^{b} \\
\omega^{b} \times J v^{b}
\end{array}\right]=\left[\begin{array}{c}
F^{b} \\
\Gamma^{b}
\end{array}\right]
$$

$m$ adalah massa total dari quadrotor, $I \in R^{3}$ adalah matrik inersia yang ada pada quadrotor, $\omega^{b}$ dan $v^{b}$ merupakan notasi dari kecepatan putar dan kecepatan translasi dari badan quadrotor. $I \in R^{3}$ merupakan matrik identitas, $F^{b}$ dan $\Gamma^{b}$ adalah verktor gaya dan momentum pada quadrotor. Bentuk dari matrik-matrik dan vektor-vektor ini terdapat pada persamaan 7

$$
\begin{gathered}
J=\left[\begin{array}{ccc}
J_{x x} & 0 & 0 \\
0 & J_{y y} & 0 \\
0 & 0 & J_{z z}
\end{array}\right] I=\left[\begin{array}{ccc}
1 & 0 & 0 \\
0 & 1 & 0 \\
0 & 0 & 1
\end{array}\right] \omega^{b}=\left[\begin{array}{c}
\omega_{x} \\
\omega_{y} \\
\omega_{z}
\end{array}\right] \\
F^{b}=\left[\begin{array}{l}
F_{x} \\
F_{y} \\
F_{z}
\end{array}\right] v^{b}=\left[\begin{array}{l}
v_{x} \\
v_{y} \\
v_{z}
\end{array}\right] \quad \Gamma^{b}=\left[\begin{array}{c}
\tau_{x} \\
\tau_{y} \\
\tau_{z}
\end{array}\right]
\end{gathered}
$$

Persamaan 7 , aturan $\omega^{b} \times m v^{b}$ dapat diabaikan ketika quadrotor bergerak dengan perlahan. Gaya thrust, $T_{i}$ dan gaya $d r a g, D_{i}$ adalah proporsional dengan kuadrat dari kecepatan baling-baling. Kecepatan dari motor dinotasikan dengan simbol $\Omega_{i}$, i adalah nomor urut motor.

$$
\begin{aligned}
& T_{i}=C_{T} \rho A r^{2} \Omega_{i}^{2} \\
& D_{i}=C_{D} \rho A r^{2} \Omega_{i}^{2}
\end{aligned}
$$

$C_{T}$ adalah koefisien thrust, $C_{D}$ adalah koefisien drag. $A, \rho$ dan $r$ merupakan luas dari baling-baling, kerapatan udara dan jarijari baling-baling yang digunakan. Dapat direpresentasikan orientasi dari quadrotor terhadap frame bumi yang ditunjukkan pada persamaan (10).

$$
\begin{gathered}
R_{x}(\phi)=\left[\begin{array}{ccc}
1 & 0 & 0 \\
0 & \cos \phi & -\sin \phi \\
0 & \sin \phi & \cos \phi
\end{array}\right] R_{y}(\theta)=\left[\begin{array}{ccc}
\cos \theta & 0 & \sin \theta \\
0 & 1 & 0 \\
-\sin \theta & 0 & \cos \theta
\end{array}\right] \\
R_{z}(\psi)=\left[\begin{array}{ccc}
\cos \psi & -\sin \psi & 0 \\
\sin \psi & \cos \psi & 0 \\
0 & 0 & 1
\end{array}\right] \\
R_{E}^{B}=R(\phi, \theta, \psi)=R_{z}(\psi) R_{y}(\theta) R_{x}(\phi) \\
R_{E}^{B}=\left[\begin{array}{ccc}
c \psi c \theta & c \psi s \theta s \phi-c \phi c \psi & c \psi s \theta c \phi+s \psi s \phi \\
s \phi c \theta & s \psi s \theta s \phi+c \psi c \phi & s \psi s \theta c \phi-s \phi c \psi \\
-s \theta & s \phi c \theta & c \theta c \phi
\end{array}\right]
\end{gathered}
$$

Pada persamaan (6), gaya yang bekerja pada quadrotor dapat ditransformasikan kedalam koordinat frame bumi. $E_{z}$ melambangkan vektor dari sumbu z.

$$
R_{E}^{B} F^{B}=m g E_{z}-R_{E}^{B} \sum_{i=1}^{4} T_{i}
$$

Selain itu momentum yang terjadi pada sistem berhubungan dengan frame badan quadrotor dapat dicapai dengan 
menambahkan efek dari baling-baling seperti yang terlihat pada Persamaan (12)

$$
\Gamma^{b}=J \dot{\omega}^{b}+\omega^{b} \times I \omega^{b}
$$

Dan persamaan dinamika dari quadrotorpada gerak translasi dan rotasi dapat dituliskan pada persamaan

$$
\begin{gathered}
\ddot{x}=(\cos \phi \sin \theta \cos \psi+\sin \phi \sin \psi) \frac{U_{1}}{m} \\
\ddot{y}=(\cos \phi \sin \theta \cos \psi-\sin \phi \sin \psi) \frac{U_{1}}{m} \\
\ddot{z}=-g+(\cos \phi \cos \theta) \frac{U_{1}}{m} \\
\ddot{\phi}=\frac{I_{y y}-I_{z z}}{I_{x x}} q r+\frac{J r}{I_{x x}} q \Omega+\frac{U_{2}}{I_{x x}} \\
\ddot{\theta}=\frac{I_{z z}-I_{x x}}{I_{y y}} p r-\frac{J r}{I_{y y}} p \Omega+\frac{U_{3}}{I_{y y}} \\
\ddot{\psi}=\frac{I_{x x}-I_{y y}}{I_{z z}} p q+\frac{U_{4}}{I_{z z}}
\end{gathered}
$$

Dari gaya-gaya yang terjadi pada tiap motor di quadrotor, dapat dihitung persamaan torsi yang terjadi pada roll, pitch, dan yaw.

$$
\begin{aligned}
& U_{1}=F_{1}+F_{2}+F_{3}+F_{4}=b\left(\Omega_{1}^{2}+\Omega_{2}^{2}+\Omega_{3}^{2}+\Omega_{4}^{2}\right) \\
& U_{2}=b l\left(-\Omega_{2}^{2}+\Omega_{4}^{2}\right) \\
& U_{3}=b l\left(\Omega_{1}^{2}-\Omega_{3}^{2}\right) \\
& U_{4}=d\left(-\Omega_{1}^{2}+\Omega_{2}^{2}-\Omega_{3}^{2}+\Omega_{4}^{2}\right)
\end{aligned}
$$

\section{METODE PENELITIAN}

Sistem pengaturan quadrotor secara sederhana dapat dilihat pada Gambar 3.

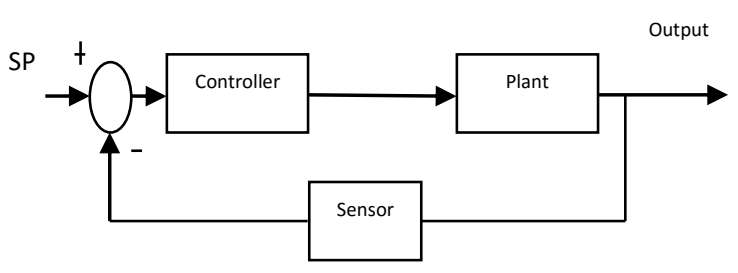

Gambar 3. Diagram blok fungsional

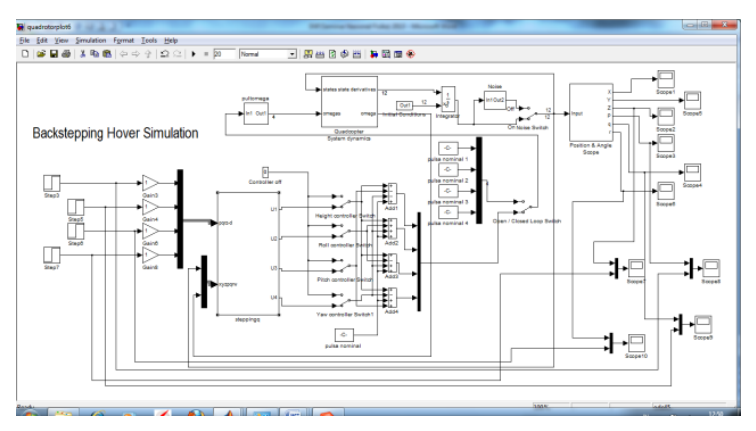

Gambar 4. Simulasi plant dan kontroller

\section{Prosedur Backstepping}

Langkah 1. menentukan tracking error

$$
e_{1}=P d s-x_{7}
$$

Langkah 2. menggunakan fungsi Lyapunov

$$
V\left(e_{1}\right)=\frac{1}{2} e_{1}^{2}
$$

Turunan dari persamaan (31)

$$
\dot{V}\left(e_{1}\right)=e_{1}(P d s-x 7)
$$

Input virtual

$$
\begin{aligned}
& e_{2}=x_{8}-\dot{P} d s-\alpha_{1} e_{1} \\
& V\left(e_{1} e_{2}\right)=\frac{1}{2}\left(e_{1}^{2}+e_{2}^{2}\right)
\end{aligned}
$$

Sehingga di dapat sinyal kontrol sebagai berikut:

$$
\begin{gathered}
U_{2}(\text { Roll })=\frac{1}{b_{1}}\left(e_{1}-a_{1} x_{10} x_{12}-a_{2} x_{10} \Omega-\right. \\
\left.\alpha_{1}\left(e_{2}+\alpha_{1} e_{1}\right)-\alpha_{2} e_{2}\right) \\
U_{3}(\text { Pitch })=\frac{1}{b_{2}}\left(e_{3}-a_{3} x_{8} x_{12}-a_{4} x_{8} \Omega-\right. \\
\left.\alpha_{3}\left(e_{4}+\alpha_{3} e_{3}\right)-\alpha_{4} e_{4}\right) \\
U_{4}(\text { Yaw })=\frac{1}{b_{3}}\left(e_{5}-a_{5} x_{8} x_{10}-\right. \\
\left.\alpha_{5}\left(e_{6}+\alpha_{5} e_{5}\right)-\alpha_{6} e_{6}\right) \\
U_{1}=\frac{m}{\cos x_{7}+\cos x_{9}}\left(e_{7}+g-\right. \\
\left.\alpha_{7}\left(e_{8}+\alpha_{7} e_{7}\right)-\alpha_{8} e_{8}\right)
\end{gathered}
$$

Dimana :

$$
e_{3}=q d s-x_{9}
$$




$$
\begin{aligned}
& e_{4}=x_{10}-\dot{q} d s-\alpha_{3} e_{3} \\
& e_{5}=r d s-x_{11} \\
& e_{6}=x_{12}-\dot{r} d s-\alpha_{5} e_{5} \\
& e_{7}=z d s-x_{5} \\
& e_{8}=x_{6}-\dot{z} d s-\alpha_{7} e_{7}
\end{aligned}
$$

\section{Parameter Quadrotor}

\begin{tabular}{|c|c|}
\hline Parameter & Nilai $($ SI) \\
\hline $\mathrm{g}$ & $9.81\left[\mathrm{~m} / \mathrm{s}^{\wedge} 2\right]$ \\
\hline $\mathrm{b}$ & $2.2478 \mathrm{e}-6 ;$ \\
\hline $\mathrm{d}$ & $2.5 \mathrm{e}-7 ;$ \\
\hline $\mathrm{m}$ & $1.2 ;[\mathrm{kg}]$ \\
\hline $\mathrm{Ixx}$ & $0.0023 ;\left[\mathrm{kg} \cdot \mathrm{m}^{\wedge} 2\right]$ \\
\hline $\mathrm{Iyy}$ & $0.0023 ;\left[\mathrm{kg} \cdot \mathrm{m}^{\wedge} 2\right]$ \\
\hline $\mathrm{Izz}$ & $0.0015 ;\left[\mathrm{kg} \cdot \mathrm{m}^{\wedge} 2\right]$ \\
\hline $\mathrm{Jr}$ & $3.3750 \mathrm{e}-5 ;$ \\
& {$\left[\mathrm{kg} \cdot \mathrm{m}^{\wedge} 2\right]$} \\
\hline $\mathrm{l}$ & $0.254 ;[\mathrm{m}]$ \\
\hline Alpha & $>0$ \\
\hline
\end{tabular}

\section{HASIL PENELITIAN}

Beberapa hasil simulasi ditampilkan dalam paper ini untuk menunjukkan performansi dari kontrol backstepping PD PI dalam mengatur sistem quadrotor.
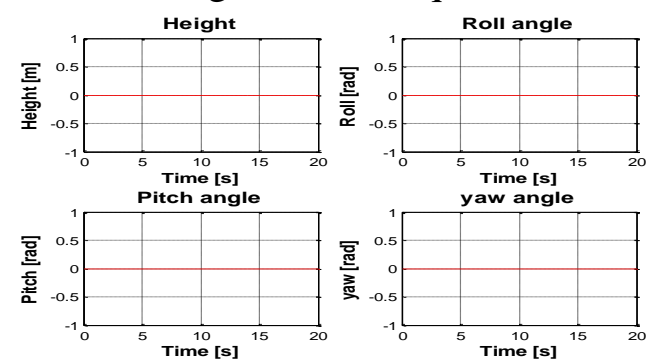

Gambar 5. Simulasi quadrotor open loop

Pada gambar 5 menunjukkan grafik respon keluaran dari quadrotor tanpa pengontrol (open-loop). Grafik respon ketinggian (z) setpoint $0 \mathrm{~m}$, sudut roll setpoint $0 \mathrm{rad} / \mathrm{s}$, sudut pitch dengan set point $0 \mathrm{rad} / \mathrm{s}$ dan sudut yaw dengan setpoint $0 \mathrm{rad} / \mathrm{s}$.
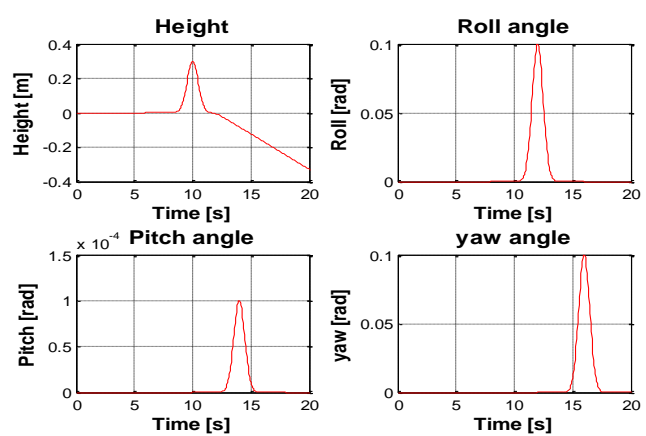

Gambar 6. Simulasi quatrotor open loop dengan gangguan

Pengujian simulasi sistem quadrotor open loop yang ditunjukkan pada gambar 6 dengan gangguan fluktuatif atau kontinew pada $\mathrm{z}=0.3 \mathrm{~m}(10 \%)$ pada detik ke $10 \mathrm{rad} / \mathrm{s}$, sudut $\mathrm{roll}=0.1 \mathrm{rad} / \mathrm{s}$ pada detik ke 12 , sudut pitch $=0,0001 \mathrm{rad} / \mathrm{s}$ pada detik ke 14 , dan sudut yaw $=0.1 \mathrm{rad} / \mathrm{s}$ pada detik ke 16 , menunjukkan bahwa sistem tidak mampu mengatasi gangguan yang dapat dilihat pada grafik respon dimana nilai ketinggian (z) mulai turun pada detik ke 12 yang besarnya sekitar $0.4 \mathrm{~m}(400 \mathrm{~cm})$.
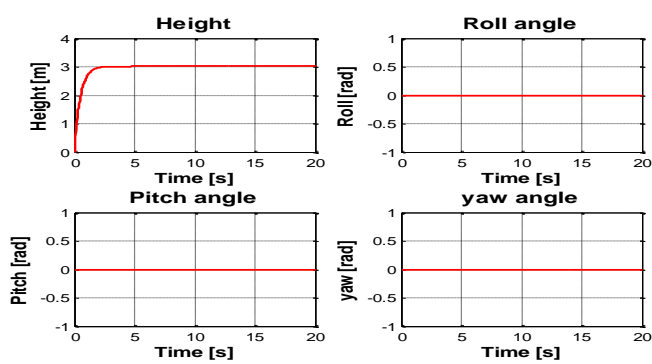

Gambar 7. Respon Ketinggian (Z), Sudut Roll, Pitch, dan Yaw Menggunakan Kontrol Backstepping Dengan Setpoint $\mathrm{Z}=3$.

Pengujian dengan kontrol backstepping dengan setpoint ketinggian $(\mathrm{z}=3)$, sudut roll, pitch, dan yaw nol, dengan initial condition nol hasil menunjukkan pada ketinggian (z) ada error sebesar 0.0156 m,sedangkan sudut roll, pitch, dan yaw hasil tetap nol tanpa error. 

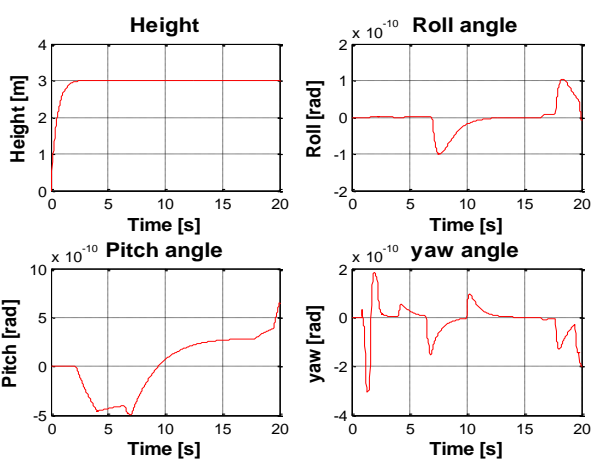

Gambar 8. Simulasi quatrotor close loop dengan kontrol backstepping PD PI

Pada gambar 6 menunjukkan grafik respon keluaran dari quadrotor close loop dengan kontrol backstepping PD PI. Grafik respon ketinggian (z) setpoint $3 \mathrm{~m}$, sudut roll setpoint $0 \mathrm{rad} / \mathrm{s}$, sudut pitch dengan set point $0 \mathrm{rad} / \mathrm{s}$ dan sudut yaw dengan setpoint $0 \mathrm{rad} / \mathrm{s} . P a d a$ respon ketinggian (z) untuk mencapai stabil steady state lumayan cepat sekitar 2 s dengan error steady state yang sangat kecil yaitu $0.0132 \mathrm{~m}$. Kemudian untuk sudut roll, pitch dan yaw meskipun grafik osilasi sebenarnya stabil karena nilainya sangat kecil yaitu $10^{-10}$ jadi dianggap nol.
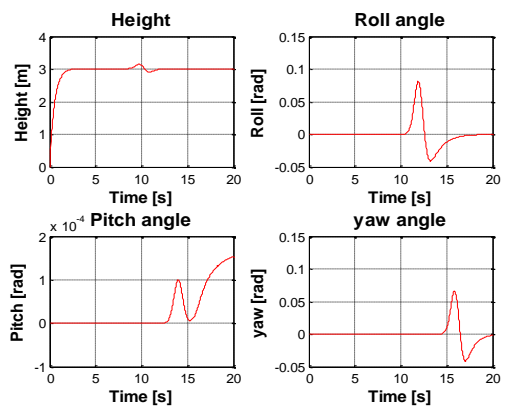

Gambar 9. Simulasi quadrotor close loop dengan kontrol backstepping PD PI dengan gangguan pada output

Pengujian simulasi sistem quadrotor pada output dengan gangguan pada $\mathrm{z}=0.3$ $(10 \%)$ pada detik ke 10 , sudut roll $=0.1$ $\mathrm{rad} / \mathrm{s}$ pada detik ke 12, sudut pitch = $0.0001 \mathrm{rad} / \mathrm{s}$ pada detik ke 14 , dan sudut yaw $=0.1 \mathrm{rad} / \mathrm{s}$ pada detik ke 16 , menunjukkan bahwa kontroller backstepping PD PI mampu memperbaiki respon meskipun ada gangguan dengan error steady state yang sangat kecil yaitu sekitar $0.0132 \mathrm{~m}$.

\section{KESIMPULAN}

Dalam paper ini dirancang metode backstepping untuk mengatur ketinggian $(\mathrm{z})$ dan untuk mengatur sudut roll, sudut pitch dan sudut yaw pada sistem quadrotor. Hasil respon menunjukkan bahwa ada gangguan maupun tanpa gangguan ada error steady state $0.0156 \mathrm{~m}$ pada ketinggian (z) sedangkan respon sudut roll, pitch, yaw tetap stabil nol. Kemudian untuk memperbaiki respon ketinggian ditambah kontrol PD PI. Dengan menggunakan kontrol backstepping PD PI menunjukkan error steady state menurun menjadi 0.0132. Ini berarti metode backstepping PD PI mampu mengatur atau mengembalikan secara cepat ke kondisi set point saat ada gangguan maupun tidak dengan error lebih kecil.

\section{DAFTAR PUSTAKA}

[1] Luukkonen, Teppo. 2011. Modelling and control quadcopter, Aalto University : Espoo.

[2] Huang, M., Xian, B., Diao, C., Yang, K. and Feng, Y. 2010. Adaptive Tracking Control of Underactuated Quadrotor Unmanned Aerial Vehicles via Backstepping, American Control Conference Marriott Waterfront, Baltimore, MD, USA

[3] Bresciani,Tommaso. 2008. Modelling, Identification and Control of $a$ Quadrotor Helicopter, Department of Automatic Control Lund University

[4] Jing Zhou, Changyun Wen. 2008. Adaptive Backstepping Control of Uncertain Systems. Springer-Verlag Berlin Heidelberg

[5] Ogata, Katsuhiko dan Leksono, Edi. 1984. Teknik Kontrol Automatik (Sistem Pengaturan)". Jilid 1. Erlangga. 
[6] Astrom, Karl Johan dan Wittenmark, Bjorn. 1989. Adaptive Control, Addison-Wesley Publishing Company, Inc.

[7] Madani, T. and Benallegue, A. 2006. Backstepping Control for a Quadrotor Helicopter, Proc. of the 2006 IEEE/RSJ International Conference on Intelligent Robots and Systems, Beijing, China.

[8] Kardono. 2012. Perancangan dan Implementasi Sistem Pengaturan Optimal LQR untuk Menjaga Kestabilan Hover pada Quadcopter.
Tugas Akhir, Institut Teknologi Sepuluh Nopember, Surabaya.

[9] Sudewo, Teddy. 2012. Desain dan Implementasi Kontrol PID Model Reference Adaptive Control untuk Automatic Safe Landing pada Pesawat UAV Quadrotor. Tugas Akhir, Institut Teknologi Sepuluh Nopember, Surabaya. 